\title{
Cost-Benefit Analysis of Plug-In Hybrid Electric Vehicle Technology*
}

\author{
Tony Markel** and Andrew Simpson***
}

\begin{abstract}
Plug-in hybrid electric vehicles (PHEVs) have emerged as a promising technology that uses electricity to displace petroleum consumption in the vehicle fleet. This paper presents a comparison of the costs (vehicle purchase costs and energy costs) and benefits (reduced petroleum consumption) of PHEVs relative to hybrid electric and conventional vehicles. A detailed simulation model is used to predict petroleum reductions and costs of PHEV designs compared to a baseline midsize sedan. The analysis finds that petroleum reductions exceeding $45 \%$ per vehicle can be achieved by PHEVs equipped with $20 \mathrm{mi}(32 \mathrm{~km})$ or more of energy storage. However, the long-term incremental costs of these vehicles are projected to exceed US\$8,000. A simple economic analysis is used to show that high petroleum prices and low battery costs are needed to make a compelling business case for PHEVs in the absence of other incentives. However, the large petroleum reduction potential of PHEVs provides strong justification for governmental support to accelerate the deployment of PHEV technology.
\end{abstract}

Keywords: Plug-In Hybrid; Hybrid Electric Vehicles; Battery, Modeling, Simulation; Energy Security.

\section{INTRODUCTION TO PLUG-IN HYBRID ELECTRIC VEHICLES}

Plug-in hybrid electric vehicles have recently emerged as a promising alternative that uses electricity to displace a significant fraction of fleet petroleum consumption [1]. A plug-in hybrid electric vehicle (PHEV) is a hybrid electric vehicle (HEV) with the ability to recharge its electrochemical energy storage with electricity from an off-board source (such as the electric utility grid). The vehicle can then drive in a charge-depleting (CD) mode that reduces the system's state-of-charge (SOC), thereby using electricity to displace liquid fuel that would otherwise have been consumed. This liquid fuel is typically petroleum (gasoline or diesel), although PHEVs can also use alternatives such as biofuels or hydrogen. PHEV batteries typically have larger capacity than those in HEVs so as to increase the potential for petroleum displacement.

\subsection{Plug-In Hybrid Electric Vehicle Terminology}

Plug-in hybrid electric vehicles are characterized by a "PHEVx" notation, where " $x$ " typically denotes the vehicle's all-electric range (AER) - defined as the distance in miles that a fully-charged PHEV can drive before needing to operate its engine. The California Air Resources Board uses the Urban Dynamometer Driving Schedule (UDDS) to measure the AER of PHEVs and provide a fair comparison between vehicles [2]. By this definition, a PHEV20 can drive $20 \mathrm{mi}(32 \mathrm{~km})$ all-electrically on the test cycle before the first engine turn-on. However, this

\footnotetext{
** National Renewable Energy Laboratory, 1617 Cole Blvd. Golden, CO 80401, e-mail:tony_markel@nrel.gov

*** Tesla Motors (formerly at NREL), 1050 Bing Street, San Carlos CA 94070, e-mail:asimpson@teslamotors.com
}

all-electric definition discounts PHEVs that might continue to operate in CD-mode after the first engine turn-on. Therefore, the authors use a definition of PHEVx that is more appropriately related to petroleum displacement. By this definition, a PHEV20 contains enough useable energy storage in its battery to displace $20 \mathrm{mi}(32 \mathrm{~km})$ of petroleum consumption on the standard test cycle. Note that this definition does not imply all-electric capability since the vehicle operation will ultimately be determined by component power ratings and their control strategy, as well as the actual in-use driving cycle.

\subsection{Plug-In Hybrid Electric Vehicle Potential}

The potential for PHEVs to displace fleet petroleum consumption derives from several factors. First, PHEVs are potentially well-matched to motorists' driving habits - in particular, the distribution of distances traveled each day. Fig. 1 shows the US vehicle daily mileage distribution based on data collected in the 1995 National Personal Transportation Survey (NPTS) [3]. Clearly, the majority of daily mileages are relatively short, with $50 \%$ of days being less than $30 \mathrm{mi}(48 \mathrm{~km})$. Fig. 1 also shows the Utility Factor (UF) curve for the 1995 NPTS data. For a certain distance $\mathrm{D}$, the UF is the fraction of total vehicle-miles-traveled (VMT) that occurs within the first D miles of daily travel. For a distance of $30 \mathrm{mi}(48 \mathrm{~km})$, the UF is approximately $40 \%$. This means that an all-electric PHEV30 can displace petroleum consumption equivalent to $40 \%$ of VMT, (assuming the vehicle is fully recharged each day). Similarly, an all-electric PHEV60 can displace about $60 \%$. This low-daily-mileage characteristic is why PHEVs have potential to displace a large fraction of per-vehicle petroleum consumption.

*This work has been authored by an employee or employees of the Midwest Research Institute under Contract No. DE-AC36-99GO10337 with the U.S. Department of Energy. The United States Government retains and the publisher, by accepting the article for publication, acknowledges that the United States Government retains a non-exclusive, paid-up, irrevocable, worldwide license to publish or reproduce the published form of this work, or allow others to do so, for United States Government purposes 


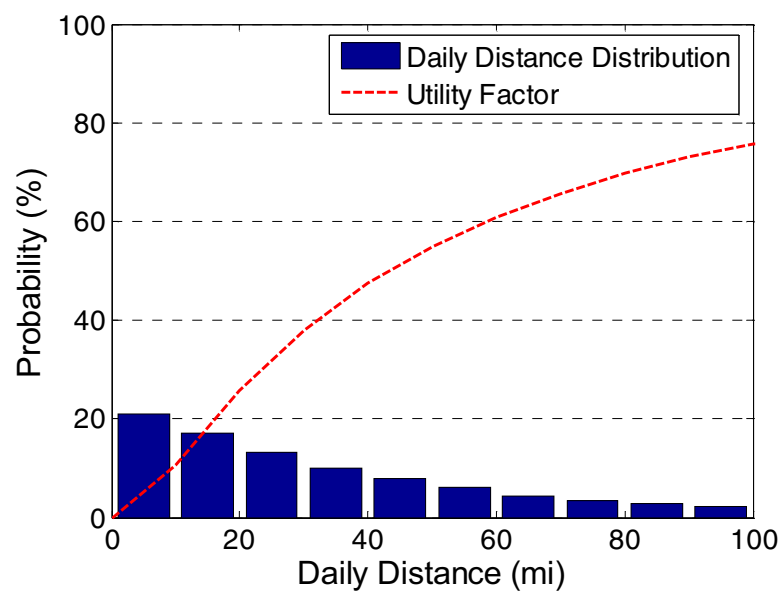

Fig. 1: Daily mileage distribution for US motorists based on 1995 National Personal Travel Survey

However, for PHEVs to displace fleet petroleum consumption, they must penetrate the market and extrapolate these savings to the fleet level. PHEVs are very marketable in that they combine the beneficial attributes of HEVs and battery electric vehicles (BEVs) while mitigating their disadvantages. Production HEVs achieve high fuel economy, but they are still designed for petroleum fuels and do not enable fuel substitution/flexibility. PHEVs, however, are true fuel-flexible vehicles that can run on petroleum or electrical energy. BEVs do not require any petroleum, but are constrained by battery technologies resulting in limited driving ranges, significant battery costs, and lengthy recharging times. PHEVs have a smaller battery which mitigates battery cost and recharging time while the onboard petroleum fuel tank provides driving range equivalent to conventional and hybrid vehicles. This combination of attributes is building a strong demand for PHEVs, as evidenced by the recently launched Plug-In Partners Campaign [4].

PHEVs have the potential to come to market, penetrate the fleet, and achieve meaningful petroleum displacement relatively quickly. Few competing technologies offer this potential combined rate and timing of reduction in fleet petroleum consumption [5]. However, PHEV technology is not without its challenges. Energy storage system cost, volume, and life are major obstacles that must be overcome for these vehicles to succeed. Given that HEVs are succeeding in the market, the question relevant to PHEVs is, "What incremental petroleum reductions can be achieved at what incremental costs?" These factors will critically affect the marketability of PHEVs through their purchase price and cost of ownership. This paper presents the results of a study designed to evaluate this cost-benefit tradeoff.

\section{MODELING PHEV PETROLEUM CONSUMPTION AND COST}

The reduction of per-vehicle petroleum consumption in a PHEV results from two factors:
1. CD-mode petroleum displacement due to battery energy capacity of the vehicle

2. Charge-sustaining (CS)-mode fuel-efficiency improvement due to hybridization or battery power capability of the vehicle.

HEVs do not have a CD-mode and are only able to realize savings via the CS-mode. For a PHEVx, these two factors can be combined mathematically as follows:

$$
\frac{F C_{P H E V x}}{F C_{C V}}=[1-U F(x)] \frac{F C_{C S}}{F C_{C V}}
$$

where $\mathrm{FC}_{\mathrm{PHEV} x}$ is the UF-weighted fuel consumption of the PHEVx, $\mathrm{FC}_{\mathrm{CV}}$ is the fuel consumption of the reference conventional (non-hybrid) vehicle, and $\mathrm{FC}_{\mathrm{CS}}$ is the PHEVx's CS-mode fuel consumption. Note that this expression becomes approximate for PHEVs without all-electric capability because use of the utility factor in this way assumes that no petroleum is consumed in the first $x$ miles of travel.

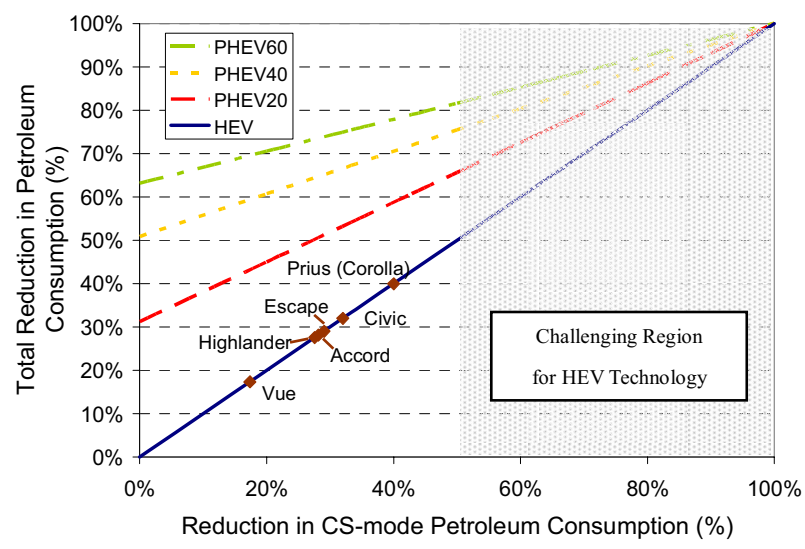

Fig. 2: Potential per-vehicle reduction of petroleum consumption in PHEVs

Fig. 2 uses Eq. 1 to compare the petroleum reduction of various PHEV designs. We see there are a variety of ways to achieve a target level of petroleum reduction. For example, a 50\% reduction is achieved by an HEV with 50\% reduced fuel consumption, a PHEV20 with 30\% CS-mode reduction, and by a PHEV40 with $0 \%$ CS-mode reduction (this last example is unlikely, since PHEVs will show CS-mode improvement due to hybridization, notwithstanding the increase in vehicle mass from the larger battery). To demonstrate the feasible range of CS-mode reduction, Fig. 2 compares several contemporary HEVs to their conventional counterparts. The "mild" HEV Saturn Vue achieves a modest reduction of less than $20 \%$. The "full" HEV Toyota Prius (relative to Corolla) achieves the highest percentage reduction (40\%) of all HEVs currently on the market although, in addition to the platform enhancements employed in production hybrids, it also uses an advanced (Atkinson-cycle) engine technology. Note that none of the production HEVs achieve the $50 \%$ reduction discussed in the above example, suggesting that there is an upper limit on the benefit of hybridization alone. 
Reductions exceeding 50\% are available through CD-mode operation in a PHEV.

The PHEV design space in Fig. 2 characterized by $\mathrm{CS} / \mathrm{CD}$-mode fuel consumption has a matching space characterized by battery power/energy. Improving CS-mode fuel consumption implies an increase in DOH (defined as the ratio of motor power to total of motor and engine power) and battery power, while increasing CD-mode benefit implies an increase in PHEVx and useable battery energy. Moving in either direction incurs additional vehicle costs. However, the link between battery specifications, $\mathrm{CS} / \mathrm{CD}$-mode reductions, and vehicle costs is not obvious and must be explored through detailed vehicle fuel consumption and cost modeling. Therefore, a model was developed to predict the petroleum reductions and costs of contrasting PHEV designs compared to a reference conventional vehicle. The details of this model are presented in the following sections.

\subsection{Modeling Approach and Scope of the Study}

The PHEV cost-benefit model includes several sub-models. First, a performance model calculates component sizes necessary to satisfy the performance constraints listed in Table 1. Second, a mass balance calculates the vehicle mass based on component sizes determined by the performance model. Third, an energy-use model simulates the vehicle's gasoline and electricity consumption over various driving cycles. The vehicle performance and energy-use models are coupled to vehicle mass, so the model is able to capture mass compounding in the sizing of components. Fourth, a cost model estimates the vehicle retail price based on the component sizes. All costs are reported in 2006 U.S. dollars. Finally, the results post-processing performs calculations to report the vehicle energy consumption and operating costs in meaningful ways. The model is implemented in an iterative Microsoft Excel spreadsheet.

The energy-use model is a detailed, second-by-second, dynamic vehicle model that uses a reverse-calculation approach [6]. It is also characterized as a power-flow model, since it models component losses/efficiencies as functions of device power, rather than as functions of torque/speed or current/voltage as in more detailed models. The reverse-calculation, power-flow method provides rapid estimation of vehicle energy usage and enables the coupled, iterative spreadsheet described above. A solution is obtained in only a few seconds, so the tool was used to evaluate several hundred PHEV designs in the study.

The model performs simulations of both conventional vehicles (CVs) and HEVs (including PHEVs) so that side-by-side comparisons can be made. The performance and energy-use models were validated for a Toyota Camry sedan and Honda Civic hybrid. In both cases, errors of less than $5 \%$ were observed in the estimates of vehicle performance and energy use.

\subsection{Platform, Performance and Cost Assumptions}

A long-term powertrain technology scenario was considered in the study. The long-term scenario
(2015-2020) allows for advanced technologies expected to result from ongoing $\mathrm{R} \& \mathrm{D}$ efforts and high-volume production levels. The long-term scenario does not, however, include advanced engine technologies since the author wanted to isolate the impact of improved electric drive and energy storage technologies on the relative cost-benefit of PHEVs.

Table 1: Vehicle Platform and Performance

\begin{tabular}{|ll}
\hline Platform Parameters & $905 \mathrm{~kg}$ \\
Glider Mass & $1429 \mathrm{~kg}$ \\
Curb Mass & $1565 \mathrm{~kg}(136 \mathrm{~kg} \mathrm{load})$ \\
Test Mass & 1899 (470 kg load) \\
Gross Vehicle Mass (GVM) & 0.3 \\
Drag coefficient & $2.27 \mathrm{~m} 2$ \\
Frontal area & 0.009 \\
Rolling resistance coefficient & $800 \mathrm{~W}$ elec. (4000 W peak) \\
Baseline accessory load & \\
Performance Parameters & $0-97 \mathrm{kph}(0-60 \mathrm{mph})$ in $8.0 \mathrm{~s}$ \\
Standing acceleration & $64-97 \mathrm{kph}(40-60 \mathrm{mph})$ in $5.3 \mathrm{~s}$ \\
Passing acceleration & $177 \mathrm{kph}(110 \mathrm{mph})$ \\
Top speed & $6.5 \%$ at $88 \mathrm{kph}(55 \mathrm{mph})$ at GVM \\
Gradeability & with $2 / 3$ fuel converter power \\
& \\
Vehicle attributes & $121 \mathrm{~kW}$ \\
Engine power & $10.6 / 6.7 / 8.8 \mathrm{~L}$ per $100 \mathrm{~km}$ \\
Fuel consumption & $($ urban / highway / composite $)$ \\
& $\$ 23,392$ \\
MSRP &
\end{tabular}

All vehicles included in the study satisfied the same performance constraints and used a vehicle platform identical to the baseline CV. The baseline $\mathrm{CV}$ was a midsize sedan (similar to a Toyota Camry or Chevrolet Malibu), and relevant parameters are presented in Table 1. Attributes were based on sales-weighted average data for the top selling U.S. midsize sedans in 2003 [7]. Parameters, such as rolling resistance, accessory loads, passing acceleration, and gradeability, were engineering estimates. The baseline manufacturer's suggested retail price (MSRP) of US\$23,392 was used in combination with the powertrain cost model to estimate the baseline "glider" cost (i.e., a vehicle with no powertrain). The cost of a $121 \mathrm{~kW} \mathrm{CV}$ powertrain was estimated at US\$6,002, leading to an estimated baseline glider cost of US\$17,390.

\subsection{Powertrain Architecture}

The two things that differentiate a PHEV from an HEV are the inclusion of a $\mathrm{CD}$ operating mode and a recharging plug. Therefore, a PHEV can be implemented using any of the typical HEV architectures (parallel, series, or power-split). For this study, a parallel architecture was assumed with the ability to declutch the engine from the powertrain (Fig. 3). This parallel layout provides greater flexibility in engine on/off control compared to Honda's integrated motor assist parallel system [8] where the engine and motor are always connected. To create more flexibility in engine on/off control, it was also assumed that all accessories (including air conditioning) would be powered 
electrically from the battery.

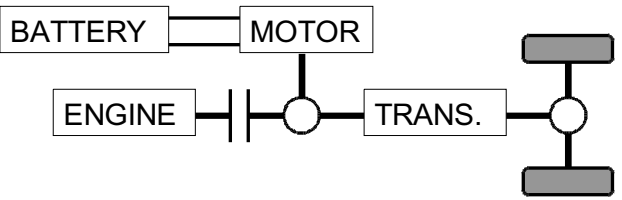

Fig. 3: Parallel HEV powertrain architecture

\subsection{Component Sizing \\ 2.4.1 Battery}

The battery is sized by two key inputs: the PHEVx designation and the battery power-to-energy $(\mathrm{P} / \mathrm{E})$ ratio. The useable battery energy is calculated using an estimate of the vehicle's equivalent electrical energy consumption per unit distance multiplied by the target PHEVx distance. The electrical energy consumption is estimated using the PAMVEC model [9]. The total battery energy is then calculated based on the SOC design window. Finally, the rated battery power is calculated by multiplying the total battery energy by the input $\mathrm{P} / \mathrm{E}$ ratio and then de-rating by $20 \%$ to account for battery power degradation at end-of-life.

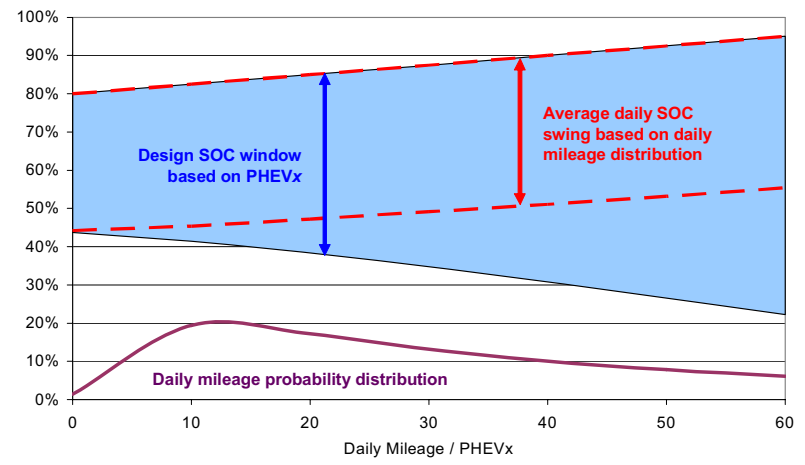

Fig. 4: SOC design window for PHEVs

To achieve similar battery cycle life, different PHEVx ranges require different SOC design windows. The daily mileage distribution (Fig. 1) means that a PHEV10 is far more likely to experience a deep cycle than a PHEV60. Therefore, the SOC design window must be chosen such that the average daily SOC swing is consistent across the range of PHEVs. Fig. 4 shows the SOC design windows assumed in the PHEV cost-benefit model, based on cycle-life data presented by Rosenkrantz [10] and a target battery life of 15 years (assuming one full recharge each day). Fig. 4 also shows the resulting average daily SOC swing, which is consistent across the range.

\subsubsection{Electric Motor}

The motor power is matched to the battery power, but with the resulting motor power being slightly smaller after accounting for electric accessory loads and motor/controller efficiency.

\subsubsection{Engine}

Several steps are required to size the engine. First, the required peak power of the engine plus motor is calculated using the PAMVEC model [9]. The peak power is typically dictated by the standing acceleration performance, and for the baseline midsize platform it is approximately $120 \mathrm{~kW}$. The motor power is then subtracted from the total to provide a requirement for the engine power. This produces some "engine downsizing," but there are downsizing limits imposed by other performance constraints. Continuous performance events (gradeability and top speed) determine the minimum permissible engine size. Gradeability performance is limited to $2 / 3$ of peak engine power due to engine thermal management and noise, vibration, and harshness considerations. For the baseline midsize platform, the minimum engine size is approximately $80 \mathrm{~kW}$.

\subsection{Component Efficiencies, Masses, and Costs 2.5.1 Engine and Electric Motor}

As discussed in Section 2.1, the PHEV energy-use model is a reverse-calculation, power-flow model that simulates component losses/efficiencies as a function of output power. Both the engine and electric motor efficiencies are modeled using polynomial expressions for component input power as a function of output power. The engine curve is based on a 4-cylinder, $1.9 \mathrm{~L}, 95 \mathrm{~kW}$ gasoline engine. A 3rd-order polynomial was fitted to data from an ADVISOR simulation [6] using this engine. The motor curve is based on a $50 \mathrm{~kW}$ permanent magnet machine, and a 9th-order polynomial was fitted to data from an ADVISOR simulation using this motor. Both efficiency curves are shown in Fig. 5.

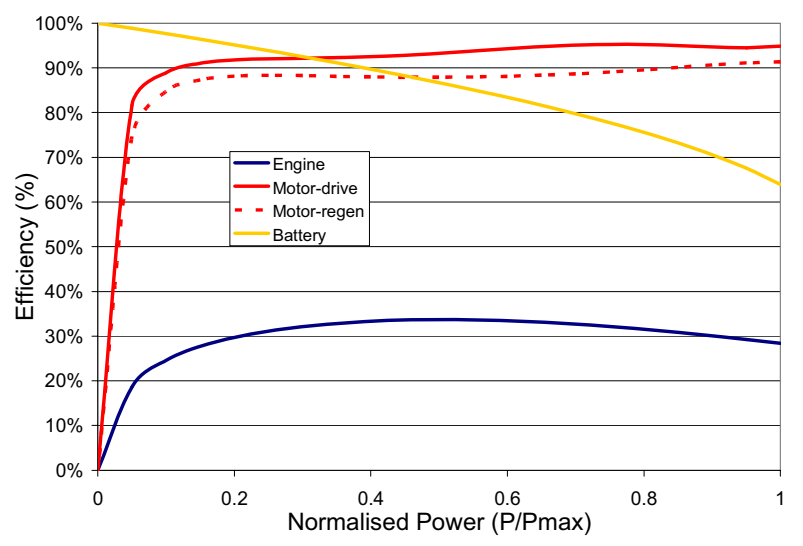

Fig. 5: Efficiency curves used in the PHEV

The engine and motor masses, and costs are modeled as linear functions of rated output power. The engine mass function is derived from a database of 2003 model-year vehicles [7]. The motor-controller mass is based on technology demonstrated in the GM Precept concept vehicle [11]. The engine cost function is based on manufacturers' data provided to the Electric Power Research Institute (EPRI) Hybrid Electric Vehicle Working Group [11]. The motor cost function, shown in Table 2, is also based on data reported by EPRI [11]. 
Table 2: Long-Term Powertrain Technology Scenario

\begin{tabular}{|l|l|}
\hline Battery & \\
\hline Chemistry & Li-Ion \\
\hline Module cost & $\$ / \mathrm{kWh}=11.1 \mathrm{x} \mathrm{P} / \mathrm{E}+211.1[11]$ \\
\hline Pack cost & $\$=(\$ / \mathrm{kWh}+13) \times \mathrm{kWh}+680[11]$ \\
\hline Module mass & Li-Ion battery design function $[12]$, see Fig. 6 \\
\hline Pack mass & Tray/straps + thermal mgmt $=0.06 \mathrm{~kg} / \mathrm{kg}[12]$ \\
\hline & Harness + bus bars $=0.14 \mathrm{~kg} / \mathrm{kW}[12]$ \\
\hline Efficiency & Equivalent circuit model based on P/E ratio, (Fig. 5) \\
\hline SOC window & $\begin{array}{l}\text { SOC design window curve, see Fig. } 4 \\
(\text { assumes Li-Ion cycle life }=\mathrm{NiMH})\end{array}$ \\
\hline Motor & \\
\hline Mass & $\mathrm{kg}=21.6+0.532 \mathrm{xW}[11]$ \\
\hline Cost & $\$=21.7 \mathrm{xW}+425[11]$ \\
\hline Efficiency & $95 \%$ peak efficiency curve, see Fig. 5 \\
\hline Engine & \\
\hline Mass & $\mathrm{kg}=1.62 \mathrm{x} \mathrm{kW}+41.8[7]$ \\
\hline Cost & $\$=14.5 \mathrm{x} \mathrm{kW}+531[11]$ \\
\hline Efficiency & $34 \%$ peak efficiency curve, see Fig. 5 \\
\hline
\end{tabular}

\subsubsection{Battery}

Battery efficiency is modeled using a normalized function for efficiency versus input power (Fig. 5). This relationship was derived from an equivalent circuit model using realistic values for nominal open-circuit voltage and internal impedance. Battery-module mass for Li-Ion technology is modeled using battery design functions developed by Delucchi [12] and shown in Fig. 6 . The added mass of battery packaging and thermal management was also based on [12].

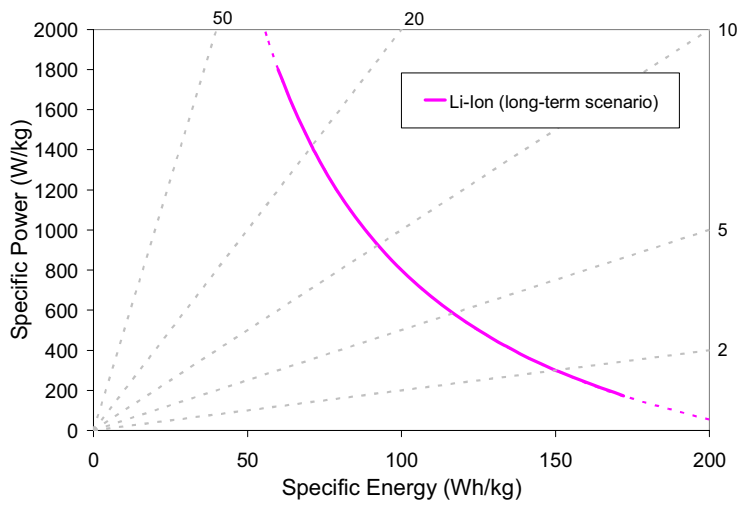

Fig. 6: Li-Ion technology battery design function

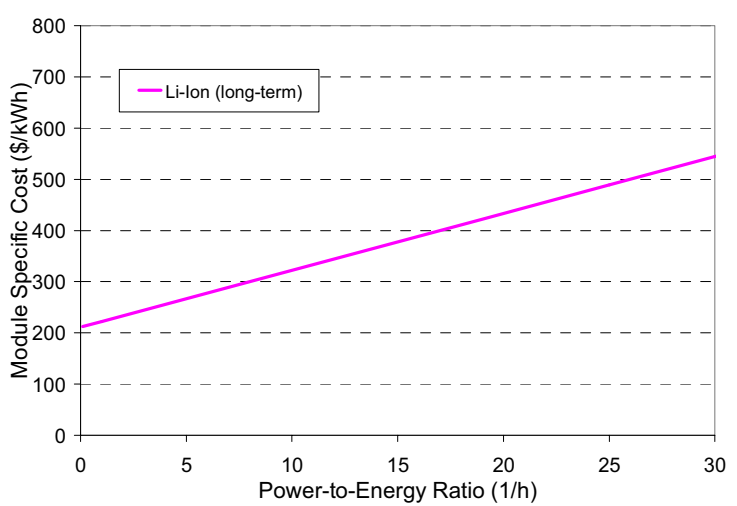

Fig. 7: Battery module cost for Li-Ion technology
Battery-module-specific costs $(\$ / \mathrm{kWh})$ vary as a function of power-to-energy ratio (Fig. 7). The long-term Li-Ion cost curve is based on estimates from EPRI [11]. The costs of battery packaging and thermal management are also based on those listed by Graham [11].

\subsubsection{Recharging Plug and Charger}

PHEVs are assumed to be equipped with an inverter-integrated plug/charger with $90 \%$ efficiency and an incremental manufactured cost of US\$380 over the baseline inverter cost [11].

\subsubsection{Retail Markup Factors}

The component cost functions in Table 2 model the manufactured cost of components. To convert these to retail costs in a vehicle, various markup factors are applied. A manufacturer's markup of $50 \%$ and dealer's markup of $16.3 \%$ are assumed based on estimates by EPRI [11].

\subsection{Powertrain Control Strategy}

A generic control strategy was developed for the spectrum of PHEV designs. This control strategy consists of four basic elements. The basis of the strategy is an SOC-adjusted engine power request:

$$
P_{\text {engine-request }}=P_{\text {driveline }}-k\left(S O C-S O C_{t a r g e t}\right)
$$

When the SOC is higher than the target, the engine power request is reduced to promote $\mathrm{CD}$ operation. Alternatively, when the SOC is lower than the target, the engine power request is increased to recharge the battery. The adjustment is governed by the factor $\mathrm{k}$, which is set proportional to total battery capacity. An electric-launch speed of $10 \mathrm{mph}(16 \mathrm{kph})$ is also specified, below which the strategy tries to operate the vehicle all-electrically by setting the engine power request to zero. However, both the SOC adjustment and electric launch can cause the power ratings of the motor to be exceeded. Therefore, a third element of the strategy is to constrain the engine power request to within acceptable limits such that no components are overloaded. Finally, there is engine on/off control logic. The engine is triggered on whenever the adjusted engine power request becomes positive. Once on, however, the engine can only turn off after it has been on for at least 5 minutes. This final constraint is designed to ensure the engine warms up thoroughly so that repeated cold starts are avoided.

The aim of this control strategy is to prioritize discharging of the battery pack. Given the nature of the daily mileage distribution, this approach ensures that the maximum petroleum will be displaced. However, the strategy does not explicitly command all-electric operation. Rather, it discharges battery energy at the limits of the battery/motor power capabilities and uses the engine as needed to supplement the road load power demand. Therefore, the vehicle behavior that results is totally dependent on the power ratings of components. Vehicles with higher electric power ratings will have all-electric capability in more aggressive driving, whereas vehicles 
with lower electric power ratings will tend to operate in a "blended" CD-mode that utilizes both motor and engine. For more discussion of all-electric and "blended" operation, the reader is directed to [13].

\subsection{Driving Cycles}

The cost-benefit model simulates CVs, HEVs, and PHEVs over two cycles - the UDDS and the Highway Fuel Economy Test (HWFET) — used by the US Environmental Protection Agency (EPA) for fuel economy and emissions testing and labeling [14].

\subsection{Fuel Economy Measurement and Reporting}

The PHEV fuel economies are determined using a modified version of the Society of Automotive Engineers' J1711 Recommended Practice for Measuring the Exhaust Emissions and Fuel Economy of Hybrid Electric Vehicles [15]. This procedure measures the fuel and electricity use in both $\mathrm{CD}$ and CS-modes and weights them according to the UF, assuming the PHEVs are fully recharged each day. Further discussion of this procedure for fuel economy measurement and reporting is provided by Gonder and Simpson [14].

\section{RESULTS}

PHEV2, 5, 10, 20, 30, 40, 50, and 60 vehicles were considered in the study. Also, an HEV0 was modeled as a PHEV2 with its charger/plug removed. $\mathrm{P} / \mathrm{E}$ ratios were chosen to vary $\mathrm{DOH}$ across a range of approximately $10 \%-55 \%$. Note that the engine downsizing limit corresponds to a $\mathrm{DOH}$ of approximately $32 \%$, and that DOH higher than this results in excess electric power capability onboard the vehicle.

Fig. 8 shows the battery specifications for the spectrum of PHEVs considered. The total battery energy varies from approximately $1.5 \mathrm{kWh}$ for the HEV0/PHEV2 to approximately $25 \mathrm{kWh}$ for the PHEV60. The battery power varies from approximately $10-100 \mathrm{~kW}$ across the range of DOH. Fig. 8 includes dashed lines of constant $\mathrm{P} / \mathrm{E}$ ratio, which varied from approximately 1-50. Fig. 8 also indicates the minimum battery power requirement (approximately $45 \mathrm{~kW}$ ) for the PHEVs to have all-electric capability on the UDDS test cycle.

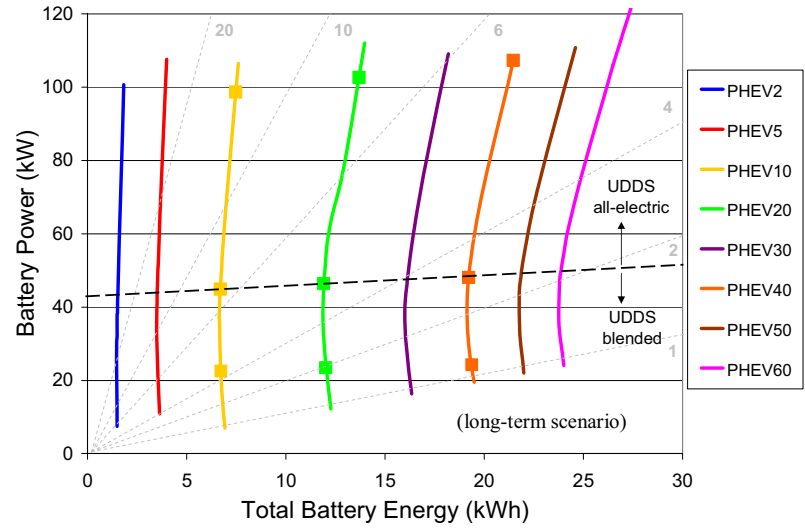

Fig. 8: PHEV design spectrum battery specifications

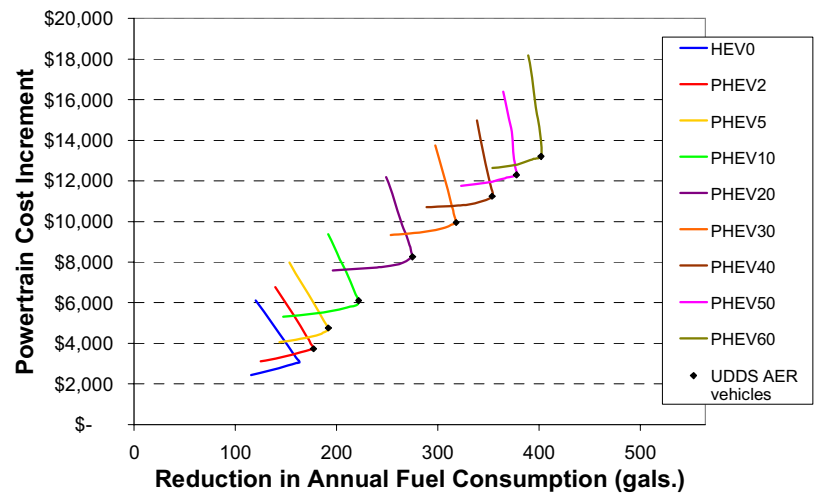

Fig. 9: Incremental costs and annual petroleum consumption for the spectrum of PHEV designs

Fig. 9 presents the reductions in annual petroleum consumption and incremental costs for the spectrum of PHEVs in the long-term scenario. Taking a macroscopic view, we see that increasing PHEVx provides increasing reduction in petroleum consumption. Relative to the baseline CV, which consumes 659 gal (2494 L) of petroleum based on $15,000 \mathrm{mi}(24,100 \mathrm{~km})$ each year, the HEVs reduce petroleum consumption by $20 \%-28 \%$. The PHEVs reduce petroleum consumption further, ranging from $21 \%-31 \%$ for the PHEV2s up to $53 \%-64 \%$ for the PHEV60s. However, these increasing reductions come at

Table 3: Long-Term Scenario PHEV Specifications - Optimum DOH Vehicles

\begin{tabular}{|c|c|c|c|c|c|c|c|c|c|c|}
\hline Vehicle & $\begin{array}{r}\text { Curb } \\
\text { Mass } \\
(\mathrm{kg})\end{array}$ & $\begin{array}{r}\text { Engine } \\
\text { Power } \\
(\mathrm{kW})\end{array}$ & $\begin{array}{r}\text { Motor } \\
\text { Power } \\
(\mathrm{kW})\end{array}$ & $\mathrm{DOH}$ & $\begin{array}{r}\text { Battery } \\
\text { Energy } \\
(\mathrm{kWh})\end{array}$ & $\begin{array}{r}\mathrm{P} / \mathrm{E} \\
\text { Ratio } \\
(1 / \mathrm{h})\end{array}$ & $\begin{array}{r}\text { SOC } \\
\text { Window }\end{array}$ & $\begin{array}{r}\text { Fuel } \\
\text { Cons. } \\
(\mathrm{L} / 100 \mathrm{~km})\end{array}$ & $\begin{array}{r}\text { Elec. } \\
\text { Cons. } \\
(\mathrm{Wh} / \mathrm{km})\end{array}$ & $\begin{array}{r}\text { Retail } \\
\text { Cost } \\
\text { (US\$) }\end{array}$ \\
\hline $\mathrm{CV}$ & 1429 & 122 & --- & --- & --- & --- & --- & 10.3 & --- & 23,392 \\
\hline HEV0 & 1412 & 77 & 36 & $32 \%$ & 1.5 & 32.8 & $37 \%$ & 7.4 & --- & 26,658 \\
\hline PHEV2 & 1412 & 77 & 36 & $32 \%$ & 1.5 & 32.8 & $37 \%$ & 7.2 & 7 & 27,322 \\
\hline PHEV5 & 1445 & 78 & 41 & $34 \%$ & 3.5 & 15.7 & $39 \%$ & 7.0 & 17 & 28,365 \\
\hline PHEV10 & 1481 & 79 & 42 & $35 \%$ & 6.6 & 8.5 & $41 \%$ & 6.5 & 32 & 29,697 \\
\hline PHEV20 & 1531 & 81 & 43 & $35 \%$ & 11.8 & 4.9 & $47 \%$ & 5.7 & 58 & 31,828 \\
\hline PHEV30 & 1569 & 82 & 44 & $35 \%$ & 15.9 & 3.7 & $53 \%$ & 5.0 & 78 & 33,533 \\
\hline PHEV40 & 1598 & 83 & 45 & $35 \%$ & 19.0 & 3.2 & $59 \%$ & 4.5 & 96 & 34,839 \\
\hline PHEV50 & 1618 & 84 & 45 & $35 \%$ & 21.6 & 2.8 & $66 \%$ & 4.1 & 108 & 35,857 \\
\hline PHEV60 & 1636 & 84 & 46 & $35 \%$ & 23.6 & 2.6 & $73 \%$ & 3.7 & 120 & 36,681 \\
\hline
\end{tabular}


increasing costs. The HEV0s are projected to cost US\$2,000-\$6,000 more than the baseline CV, whereas the PHEV60s are projected to cost US\$12,000-\$18,000 more.

Looking closely at Fig. 9, we see a repeated trend in the relative cost-benefit of PHEVs with varying $\mathrm{DOH}$, and there is an optimum DOH for each PHEVx. For the HEV0s, the optimum DOH (32\%) coincides with the limit of engine downsizing. For the PHEVs, the optimum DOH is higher $(35 \%)$ to coincide with the minimum battery power required for all-electric capability on the UDDS cycle (the maximum power requirement on the HWFET cycle is lower). All-electric capability allows vehicles to avoid engine idling losses that would otherwise be incurred due to engine turn-on events subject to the 5-minute minimum engine on time constraint. The optimum HEVs and PHEVs for the long-term scenario are summarized in Table 3.

It must be emphasized that these optimum $\mathrm{DOH}$ are highly-dependent on the vehicle platform/performance attributes and the nature of the driving pattern. The analysis should be repeated for other baseline vehicles (e.g. sport-utility vehicles) to see how the PHEV designs will vary. Furthermore, PHEVs should be simulated over real-world driving cycles to identify differences in the petroleum displacement and all-electric operation compared to standard test cycles. Such further analyses should provide the understanding needed to optimize PHEVs for the market.

\subsection{Economics of PHEVs}

The PHEV cost-benefit analysis also includes a simple comparison of cost-of-ownership over the vehicle lifetime. The comparison includes the retail cost of the vehicle and the cost of its annual energy (fuel and electricity) consumption, but does not account for possible differences in maintenance costs (for more detailed analysis of total PHEV life cycle costs, see [11]). Fig. 10 presents economic comparisons for the long-term scenario. In calculating annual petroleum and electricity consumption, all vehicles are assumed to travel $15,000 \mathrm{mi}(24,100 \mathrm{~km})$ per year to be consistent with EPA's assumptions. A near-term scenario with the cost of retail gasoline assumed to be US\$3 per gallon (US\$0.79 per L) was assessed but is not presented here. For the long-term scenario a higher gasoline cost of US\$5 per gallon (US\$1.32 per L) was assumed. The cost of retail electricity is held constant at US $\$ 0.09$ per $\mathrm{kWh}$ based on the 2005 U.S. average retail price and historical trends [16]. No discount rate was applied to future cash flows.

In the near-term scenario, the HEV achieves a lower cost-of-ownership than the CV after approximately 10 years. However, with high battery cost and low fuel cost in the near-term, the PHEVs never achieve a lower cost-of-ownership than the CV nor the HEV over the 15 -year vehicle lifetime. The long-term scenario provides a significant contrast, with the HEV providing lower cost than the $\mathrm{CV}$ after approximately 4 years and the PHEVs providing lower cost than the HEV after approximately 12 years.

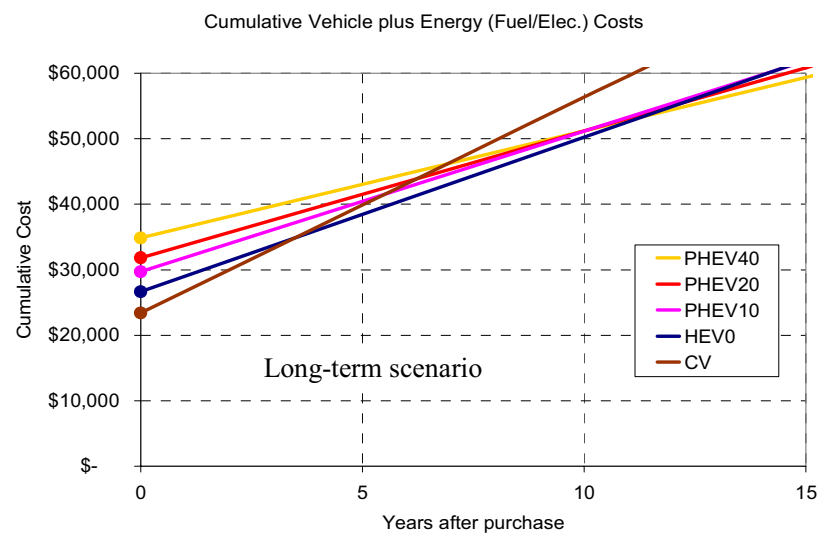

Fig. 10: Economic comparison of PHEVs

The "payback" analyses are sensitive to the cost of gasoline and also the vehicle retail costs, which are strongly affected by the battery cost assumptions. The near-term economics for PHEVs are not promising if gasoline prices remain at current levels and battery costs cannot be improved. However, there is a compelling business case for plug-in hybrids under a scenario of both higher gasoline prices and long-term projected battery costs, from the perspective of the simple consumer economic comparison presented here.

Despite the uncertainty of PHEV economics, there are other factors that may justify the incremental PHEV cost. Examples include tax incentives; reductions in petroleum use, air pollution, and greenhouse emissions; national energy security; reduced maintenance; fewer fill-ups at the gas station; convenience of home recharging; improved acceleration from high-torque electric motors; a green image; opportunities to provide emergency backup power in the home; and the potential for vehicle-to-grid applications. Alternative business models-such as battery leasing - might help to mitigate the daunting incremental vehicle cost and encourage PHEV buyers to focus on the potential for long-term cost savings.

\section{CONCLUSION}

This paper has presented a comparison of the costs (vehicle purchase costs and energy costs) and benefits (reduced petroleum consumption) of PHEVs relative to HEVs and CVs. Based on the study results, there is a very broad spectrum of HEV-PHEV designs with greatly varying costs and benefits. Furthermore, the PHEV cost-benefit equation is quite sensitive to a range of factors. In particular, battery costs, fuel costs, vehicle performance, and driving habits have a strong influence on the relative value of PHEVs. Given the large variability and uncertainty in these factors, it is difficult to predict the future potential for PHEVs to penetrate the market and reduce fleet petroleum consumption.

However, the potential for PHEVs to reduce per-vehicle petroleum consumption is very high. Reductions in excess of $45 \%$ are available using designs of PHEV20 or higher. 
This compares favorably with the $30 \%$ maximum reduction estimated for HEVs. However, it seems likely that the added battery capacity of a PHEV will result in significant vehicle cost increments, even in the long term. A long-term retail cost increment of US $\$ 3,000$ was estimated for a midsize sedan HEV. In contrast, the long-term cost increments for a midsize PHEV20 and PHEV40 were estimated at US\$8,000 and US\$11,000 respectively. Without knowing the future costs of petroleum, it is impossible to determine the future economics of PHEVs. But it does seem likely, based on the results of this study, that it will be quite a challenge to justify the PHEV capital cost premium on the basis of reduced lifetime energy costs alone. Other incentives and business models may be required to create an attractive value proposition for PHEV motorists. However, the large petroleum reduction potential of PHEVs offers significant national benefits and provides strong justification for governmental support to accelerate the deployment of PHEV technology.

\section{ACKNOWLEDGEMENT}

The authors would like to acknowledge the programmatic support of the U.S. Department of Energy Office of Energy Efficiency and Renewable Energy FreedomCAR and Vehicle Technologies Program.

\section{REFERENCES}

[1] Sanna, L.: "Driving the Solution: The Plug-In Hybrid Vehicle" EPRI Journal, 2005.

[2] California Air Resources Board, "California Exhaust Emission Standards and Test Procedures for 2005 and Subsequent Model Zero-Emission Vehicles, and 2002 and Subsequent Model Hybrid Electric Vehicles, in the Passenger Car, Light-Duty Truck and Medium-Duty Vehicle Classes," California EPA, 2003.

[3] 1995 National Personal Transportation Survey (NPTS), npts.ornl.gov/npts/1995/doc/index.shtml.

[4] Plug-In Partners online, http://www.pluginpartners.org/, accessed July 30, 2006.

[5] Markel, T., O'Keefe, M., Gonder, J., Brooker, A.: "Plug-in HEVs: A Near-term Option to Reduce Petroleum Consumption," NREL 39415, 2006.

[6] Wipke, K.B., Cuddy, M.R., Burch, S.D.: "ADVISOR 2.1: A User-Friendly Advanced Powertrain Simulation Using a Combined Backward/Forward Approach", IEEE Transactions on Vehicular Technology, Vol 48, No. 6, 1999, pp. 1751-1761.

[7] Rush, D.: "Market Characterization for Light-Duty Vehicle Technical Targets Analysis," NREL internal documents, 2003.

[8] "Honda IMA System/Power Unit," Honda online, world.honda.com/CIVICHYBRID/Technology/NewHondaI MASystem/PowerUnit/index_1.html, accessed July 30, 2006.

[9] "PAMVEC Model," University of Queensland Sustainable Energy Research Group online, www.itee.uq.edu.au/ serl/PAMVEC.html, accessed July 30, 2006.

[10] Rosenkrantz, K.: "Deep-Cycle Batteries for Plug-In Hybrid Application," EVS20 Plug-In Hybrid Vehicle Workshop, Long Beach, 2003.

[11] Graham, R.: "Comparing the Benefits and Impacts of Hybrid Electric Vehicle Options." Electric Power Research Institute (EPRI), 2001.

[12] Delucchi, M.: "Electric and Gasoline Vehicle Life Cycle Cost and Energy-Use Model," Institute of Transportation
Studies. University of California, Davis, 2000.

[13] Markel, T. and Simpson, A.: "Plug-In Hybrid Electric Vehicle Energy Storage System Design," Proc. Advanced Automotive Battery Conference, Baltimore, Maryland, 2006.

[14] Gonder, J. and Simpson, A.: "Measuring and Reporting Fuel Economy of Plug-In Hybrid Electric Vehicles," 22nd Intl. Battery, Hybrid and Fuel Cell Electric Vehicle Symposium \& Exposition, Yokohama, Japan, 2006.

[15] "SAE J1711 - Recommended Practice for Measuring Fuel Economy of Hybrid-Electric Vehicles," Society of Automotive Engineers, Warrendale, 1999.

[16] U.S. Energy Information Administration online, www.eia.doe.gov, accessed July 30, 2006.

\section{BIOGRAPHIES}

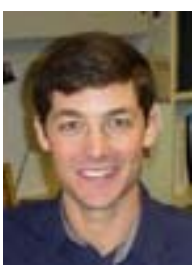

Tony Markel joined National Renewable Energy Laboratory (NREL) in 1996. He received the M.S. degree in mechanical engineering from University of Colorado in 2005 and a B.S.E degree in mechanical engineering from Oakland University in 1995 . He was instrumental in the development of the ADVISOR software tool for vehicle systems simulation and is skilled at using analysis and optimization tools to address real-world problems.

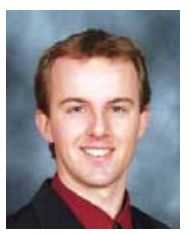

Andrew Simpson joined Tesla Motors in 2006. Prior to that he was a member of the Advanced Vehicle Systems Group at NREL. He holds a Bachelor of Mechanical Engineering (2000) and Ph.D. in Electrical Engineering (2005) from the University of Queensland, Brisbane, Australia. He co-founded the Sustainable Energy Research Group at the University of Queensland and led the "SunShark" solar car team. 